\title{
Puerperal ovarian vein thrombophlebitis
}

\author{
Lawrence C.H. Tang, Joseph S.K. Woo and Y.C. Choo \\ Department of Obstetrics and Gynaecology, University of Hong Kong, Hong Kong.
}

\begin{abstract}
Summary: A 16 year old Chinese female with puerperal ovarian vein thrombophlebitis following uneventful vaginal delivery is reported. This infrequent, but potentially fatal, complication in the febrile postpartum patient may present as a surgical emergency. Non-invasive diagnostic procedures and conservative treatment with heparinization and antibiotics have been suggested. However, early exploratory laparotomy for ovarian vein or caval ligation may be life-saving if the diagnosis is in doubt or the response to conservative treatment is unsuccessful.
\end{abstract}

\section{Introduction}

Puerperal ovarian vein thrombophlebitis (POVT) is an infrequently reported complication of the early puerperium. It usually presents as a triad of constant lower abdominal or flank pain, fever and a deep, tender mass, - the thrombosed ovarian vein, which is usually on the right side (Munswick \& Gillanders, 1981).

Brown \& Munswick (1971) suggested an incidence of 1 in 600 deliveries. Sporadic cases have also been reported in the literature, mainly in the Caucasian population. In Chinese, the occurrence of deep vein thrombosis is rare (Tso et al., 1980); it is therefore not surprising that ovarian thrombopheblitis is extremely uncommon.

\section{Case report}

A 16 year old Chinese primigravida had an uncomplicated pregnancy. She went into spontaneous onset of labour at 39 weeks' gestation. Artificial rupture of membranes was performed. The first stage of labour lasted for eight hours and forty minutes. She delivered spontaneously a female infant weighing $2,620 \mathrm{~g}$ with an Apgar score of 10 after a second stage of fifteen minutes. There were no cervical, vaginal or perineal lacerations apart from the left posterolateral episiotomy wound which was repaired with chromic catgut stitches. Delivery and examination of the

Lawrence C.H. Tang, M.B., B.S., M.R.C.O.G.; Joseph S.K. Woo, M.B., B.S., M.R.C.O.G.; Y.C. Choo, M.B., B.S., F.A.C.O.G.

Correspondence: Lawrence C.H. Tang, Department of Obstetrics and Gynaecology, University of Hong Kong, Queen Mary Hospital, Hong Kong.

Accepted: 13 December 1983 placenta were unremarkable. Estimated blood loss was $300 \mathrm{ml}$. The first postpartal week was uneventful.

On the tenth postpartal day, the patient was readmitted to hospital because of sudden onset of generalized abdominal pain which became more severe and shifted to the right lower quadrant. There was no nausea, vomiting or symptoms suggestive of urinary tract infection. The amount of lochia was not excessive or foul-smelling. The temperature was between $37.4^{\circ} \mathrm{C}$ and $38.5^{\circ} \mathrm{C}$. Abdominal examination showed marked tenderness and moderate rigidity over McBurney's point associated with generalized tenderness and rebound tenderness. The uterus was well involuted. A poorly defined mass was felt abdominally adjacent to the right cornu of the uterus. The mass was sausage-shaped and exquisitely tender. Vaginal examination revealed a normal cervix with no foul lochia, a firm uterus at half-way between umbilicus and pubic symphysis. Bimanual examination demonstrated no palpable adnexal masses with only minimal tenderness over the right fornix. The haemoglobin was $12.8 \mathrm{~g} / \mathrm{dl}$ and the white cell count was $13.3 \times 10^{9} / 1$ with $77 \%$ neutrophils and $21 \%$ lymphocytes. Urine analysis was unremarkable. The impression was acute appendicitis with appendicular mass, torsion of right ovarian cyst or tubo-ovarian abscess.

Laparotomy revealed normal appendix, normal left ovary and tube. There was a moderate amount of straw-coloured peritoneal fluid, and an oedematous and thickened right tube. The right ovary was grossly normal but a swollen and fluctuant area of $3 \mathrm{~cm}$ diameter was noted in the right broad ligament. The right ovarian vein was dilated and occluded by a thrombus of $4 \mathrm{~cm}$ long. The right infundibulo-pelvic ligament was doubly ligated after identifying the right ureter. Drainage of the right broad ligament was done. No resection of tissue was indicated. 
Parenteral administration of cefoperazone and gentamicin was started postoperatively. Heparin anticoagulation was given intravenously at the dosage of 5,000 units eight hourly for seven days. The patient recovered satisfactorily and was discharged on the eleventh postoperative day.

\section{Discussion}

The right-sided preponderance of puerperal ovarian vein thrombophlebitis (Brown \& Munsick, 1971) makes a preoperative definitive diagnosis difficult. If other surgical conditions cannot be excluded, exploratory laparotomy is mandatory. Non-invasive diagnostic procedures such as transabdominal uterine phlebogram (Munsick \& Gillanders, 1981), excretory urography (Darney \& Wilson, 1977), femoral venography (Hughey et al., 1979), pelvic and abdominal sonography and computer-assisted tomographic scanning have been suggested as possible alternatives. However, surgical intervention should not be delayed if any doubt exists.

\section{References}

BROWN, T.K. \& MUNSICK, R.A. (1971). Puerperal ovarian vein thrombophlebitis: a syndrome. American Journal of Obstetrics and Gynecology, 109, 263.

DARNEY, P.D. \& WILSON, E.A. (1977). Intravenous pyelography in the diagnosis and management of postpartum ovarian vein thrombophlebitis: a case report. American Journal of Obstetrics and Gynecology, 127, 439.

HUGHEY, M., McELIN, T.W.\& CAPRINI, J.A. (1979). Nonsurgical diagnosis and management of puerperal ovarian vein thrombophlebitis. American Journal of Obstetrics and
Medical management with heparinization and antibiotic treatment have been recommended as the mode of therapeutic regime carrying the least morbidity. Operative intervention is justified if the diag-

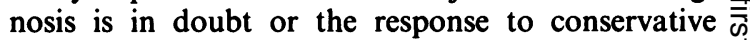
treatment is proven unsuccessful. Usually, ovarian $\overline{0}$ vein ligation will suffice, but caval ligation or $\frac{}{0}$ cavotomy is occasionally required. Prompt and $\overline{\frac{D}{2}}$ appropriate management must be instituted in order to prevent fatal pulmonary embolism.

The possibility of puerperal ovarian thrombo- 0 phlebitis should be borne in mind in the differential $\vec{\circ}$ diagnosis of patients presenting with postpartum or $\overrightarrow{\vec{H}}$ postabortal surgical emergencies. Its occurrence may $\mathcal{\sigma}^{\omega}$ not be recognized in cases of lesser severity or in $\overrightarrow{0}$ situations where the thrombosis regresses spontan- 3 . eously; and hence, its low incidence. It is considered as a distinct entity from pelvic thrombophlebitis in the $\overrightarrow{-}$ sense that the ovarian vein is solely involved. Although $\vec{N}$ embolism occurs infrequently, puerperal ovarian $\rightarrow$

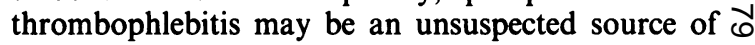
postpartum pulmonary embolism.

Gynecology, 133, 461.

MUNSICK, R.A. \& GILLANDERS, L.A. (1981). A review of the syndrome of puerperal ovarian vein thrombophlebitiș Obstetrics and Gynecology Survey, 36, 57.

TSO, S.C., WONG, V.C.W., CHAN, V.N.Y., CHAN, T.K., MA, H.K. \& TODD, D. (1980). Deep vein thrombosis and changes in coagulation and fibrinolysis after gynaecological operation in Chinese: the effect of oral contraceptives and malignant disease. British Journal of Haematology, 46, 603. 